\title{
The Effect of Symptom Onset-to-needle time on Ischemic Outcomes in Patients Treated with Primary Angioplasty in the Era of Potent Antiplatelets
}

\section{Milan Hromadka}

Department of Cardiology, University Hospital and Faculty of Medicine in Pilsen, Charles University

Zuzana Motovska ( $\sim$ motovska.zuzana@gmail.com )

Univerzita Karlova 3 lekarska fakulta https://orcid.org/0000-0002-5319-473X

\section{Ota Hlinomaz}

First Department of Internal Medicine-Cardioangiology, International Clinical Research Center, Faculty of Medicine, Masaryk University and St. Anne's University Hospital

\section{Petr Kala}

Department of Internal Medicine and Cardiology, Faculty of Medicine of Masaryk University and University Hospital Brno

\section{Ivo Varvarovsky}

Cardiology Centre Agel, Pardubice

\section{Jaroslav Dusek}

First Deparment of Internal Medicine, University Hospital Hradec Kralove, Charles University in Prague,

Faculty of Medicine in Hradec Kralove

\section{Michal Svoboda}

Institute of Biostatistics and Analyses at the Faculty of Medicine and the Faculty of Science of Masaryk University Brno

\section{Jiri Jarkovsky}

Institute of Biostatistics and Analyses at the Faculty of Medicine and the Faculty of Science of Masaryk University Brno

\section{Frantisek Tousek}

Cardiocenter - Department of Cardiology, Regional Hospital Ceske Budejovice

\section{Pavel Jansky}

Department of Anesthesiology and Resuscitation, University Hospital Kralovske Vinohrady, Prague

\section{Stanislav Simek}

Second Department of Medicine-Deparment of Cardiovascular Medicine, First Faculty of Medicine, Charles University in Prague und General University Hospital in Prague

\section{Marian Branny}

Agel Research and Training Institute, Trinec Branch, Cardiovascular Center, Podlesi Hospital, Trinec 


\section{Jan Mrozek}

Cardiovascular Department, University Hospital Ostrava

\section{Roman Miklik}

Department of Internal Medicine and Cardiology, Faculty of Medicine of Masaryk University and University Hospital Brno

\section{Richard Rokyta}

Department of Cardiology, University Hospital and Faculty of Medicine in Pilsen, Charles University

\section{Petr Widimsky}

Cardiocenter, Third Faculty of Medicine, Charles University and University Hospital Kralovske Vinohrady, Prague

\section{Research Article}

Keywords: STEMI, symptoms onset to needle time, risk stratification, P2Y12 inhibitors, ischemic endpoints

Posted Date: May 18th, 2021

DOl: https://doi.org/10.21203/rs.3.rs-452109/v1

License: (c) (i) This work is licensed under a Creative Commons Attribution 4.0 International License. Read Full License 


\section{Abstract}

Purpose: Based on previous studies with clopidogrel, the time between onset of symptoms and primary $\mathrm{PCl}$ was proven as an important prognostic factor. Our aim was to assess the effect of symptoms onset to needle time (SNT) on procedural results and on the occurrence of ischemic endpoints in primary angioplasty patients treated with potent $\mathrm{P} 2 \mathrm{Y} 12$ inhibitors.

Methods: A total of 1,131 out of 1,230 patients randomized to the PRAGUE 18 study (prasugrel vs. ticagrelor in primary angioplasty) were divided into a high and a low-risk group. The effect of defined SNT on patients' ischemic endpoints and prognosis by their risk status at admission was tested.

Results: The median SNT was 3.2 hours. Longer SNTs resulted in a more frequent incidence of TIMI flow $<3$ post $\mathrm{PCl}(p=0.015)$. There were significant differences in the occurrence of the combined ischemic endpoint among the compared SNT groups at 30 days $(p=0.032)$, and 1 year $(p=0.011)$, with the highest incidence in the $\leq 1 \mathrm{~h}$ SNT group of patients. "Latecomers" (SNT $>4 \mathrm{hs}$ ) in the high-risk group experienced more reMI within 1 year [OR $(95 \% \mathrm{Cl}) 3.23(1.09-9.62) \mathrm{p}=0.035]$; no difference was found in the low-risk group.

Conclusion: In the era of intense antithrombotic medication, stratification of STEMI patients undergoing primary angioplasty, based on initial ischemic risk assessment affected prognosis more than symptom onset to needle time. Longer time delay significantly increased the incidence of ischemic events and allcause mortality only in patients with high ischemic risk.

\section{Introduction}

The duration of ischemia is a major determinant of the extent of necrosis in patients with ST elevations acute myocardial infarction (STEMI) who are referred for primary percutaneous coronary intervention $(\mathrm{PCl})$, and therefore, a rapid diagnosis followed by urgent revascularization is crucial to reduce morbidity and mortality [1-6]. Minimizing the time between the onset of symptoms and initiation of reperfusion therapy is a key indicator of the quality of care for patients with STEMI or with a newly formed bundle branch block [7-9]. A marked reduction in symptom-to-balloon time or symptom-to-needle time (SNT), which is achieved by early pre-hospital ECG registration and immediate transport to a Cath lab facility in cases with ongoing myocardial ischemia, is associated with a survival benefit for AMI patients [8-10]. Direct transport to the nearest Cath lab (i.e., bypassing emergency or coronary units) cuts down the total time delay [11]. Given the importance of PCI in improving the survival of STEMI patients, clinical studies have focused primarily on the evaluation of door-to-balloon time [12,13] as an indicator of hospital care. Nevertheless, studies have shown that symptom-to-balloon time is a better predictor of outcomes, especially in patients with early STEMI presentations [14]. Symptom-to-balloon time, like symptom-toneedle time, reflects not only the quality and efficacy of medical care but also awareness and education of the public. 
Studies evaluating the effect of longer SNTs on patient outcomes were performed when clopidogrel was the dominant P2Y12 inhibitor [1-6]. Administration of new P2Y12 inhibitors like prasugrel or ticagrelor, compared to clopidogrel, leads to an earlier onset and stronger antiplatelet effects. The aim of this study was to examine whether the total duration of ischemia, evaluated using the SNT parameter, has any effects on $\mathrm{PCl}$ success rate and long-term ischemic outcomes in patients with AMI referred to primary PCl and treated with either prasugrel or ticagrelor, and analyze the prognostic impact of SNT according to patient profile at admission.

\section{Methods}

Our population was represented by 1,131 out of 1,230 patients from $14 \mathrm{PCl}$ centers randomized into the PRAGUE-18 Study (Prasugrel vs. Ticagrelor in Patients with Acute Myocardial Infarction Treated with Primary Percutaneous Coronary Intervention; NCT02808767[15,16]) in whom the data of symptom onset were available.

Two major analyses related to time delay were performed. Firstly, the patients were divided into the following groups according to the length of SNT: (1) SNT $\leq 1.0$ hour, (2) SNT 1.1-3.0 hours, (3) SNT 3.16.0 hours, and (4) SNT > 6 hours. Post-PCl outcomes (i.e., stent insertion success rate, lateral branch patency, and final TIMI flow in the culprit artery), occurrence of the defined ischemic endpoints used in the PRAGUE-18 Study (i.e., death, reinfarction, urgent target vessel revascularization, and stroke) and presence of cardiogenic shock were analyzed and compared between the groups.

In the second analysis, the patients were divided into 2 groups according to the degree of the initial risk of ischemic complications as proposed by the Thrombolysis In Myocardial Infarction (TIMI) investigators [17]: (1) a high-risk group (presence of at least one of the following criteria: age $>70$ years, STEMI of the anterior wall or LBBB, Killip II-IV, history of MI or CABG, systolic blood pressure $<100 \mathrm{mmHg}$ and heart rate $>100 / \mathrm{min}$ ), and (2) a low-risk group (all others). According to the TIMI Risk Score parameter "time-totreatment," using a cut-off value of 4 hours, patients were subsequently divided into "early comers" (SNT $\leq 4$ hours) and "latecomers" (SNT > 4 hours). An occurrence of ischemic endpoints at 30 days and 1 year was evaluated and compared between the groups.

\section{Statistical analysis}

Absolute and relative frequencies were used to describe the categorical parameters. Continuous characteristics were described by $\mathrm{N}$ and medians (5th and 95th percentiles). Differences between categorical parameters were tested using the Fisher's exact test, and differences between continuous characteristics were tested using the Mann-Whitney test (when comparing two groups) and the KruskalWallis test (when comparing multiple groups). A p-value $<0.05$ was considered statistically significant. The relationship between SNT in high and low-risk patients and the occurrence of the combined ischemic endpoint (i.e., cardiovascular death, non-fatal myocardial infarction, and stroke), recurrent AMI, cardiovascular death, and all-cause mortality at 30 and 365 days were computed using logistic 
regression and described using odds ratios and $95 \%$ confidence intervals. The analysis was performed using IBM SPSS Statistics 25.0.0.1.

\section{Results}

The median SNT was 3.2 hours $(1.1 ; 34.3)$. Women had significantly longer SNTs than men (median 3.8 vs. 3.1 hours, $p<0.001$ ). Hypertension was associated with longer SNTs in both men and women (median 3.4 vs. 3.1 hours, $p=0.008$ ). Obesity was a factor that prolonged SNT in women (median 5.3 vs. 3.5 hours, $p=0.001$ ). A history of previous MI or CABG did not significantly affect time delay.

Post-PCI TIMI flow < 3 (suboptimal flow) in the culprit artery was significantly more frequent in subjects with longer SNTs $(p=0.015)$ (Table 1). The incidence of ischemic endpoints was low in our patient cohort. CV death and the combined ischemic endpoint occurred in $1.8 \%(\mathrm{~N}=20)$ and $3.0 \%(\mathrm{~N}=34)$ at 30 days, and in $2.9 \%(\mathrm{~N}=33)$ and $5.9 \%(\mathrm{~N}=67)$ at one year. 
Table 1

Patient characteristics and intervals from symptoms onset to coronary angiography Symptom onset to needle time (hours)

Pvalue

\section{Characteristics}

Numer of patients

Age (years)

Men

Admission

STEMI

LBBB

RBBB

NSTEMI

Killip classification

61.7 (35.9;

78.7)

$1.1-3.0 h$

$43(89.6 \%)$
476

$61.4(43.4$

77.4)

$375(78.8 \%)$

\begin{tabular}{|c|c|c|c|c|c|c|}
\hline STEMI & & $43(89.6 \%)$ & $461(96.8 \%)$ & $287(93.5 \%)$ & $255(85.0 \%)$ & $\begin{array}{l}< \\
0.001\end{array}$ \\
\hline LBBB & & $0(0.0 \%)$ & $4(0.8 \%)$ & $4(1.3 \%)$ & $9(3.0 \%)$ & 0.124 \\
\hline RBBB & & $1(2.1 \%)$ & $10(2.1 \%)$ & $5(1.6 \%)$ & $5(1.7 \%)$ & 0.909 \\
\hline NSTEMI & & $4(8.3 \%)$ & $9(1.9 \%)$ & $13(4.2 \%)$ & $34(11.3 \%)$ & $\begin{array}{l}< \\
0.001\end{array}$ \\
\hline \multirow[t]{4}{*}{ Killip classification } & 1 & $32(66.7 \%)$ & $417(87.6 \%)$ & $284(92.5 \%)$ & $264(88.0 \%)$ & \multirow{4}{*}{$\delta_{0.001}^{<}$} \\
\hline & II & $4(8.3 \%)$ & $39(8.2 \%)$ & $13(4.2 \%)$ & $22(7.3 \%)$ & \\
\hline & III & $1(2.1 \%)$ & $6(1.3 \%)$ & $4(1.3 \%)$ & $5(1.7 \%)$ & \\
\hline & IV & $11(22.9 \%)$ & $14(2.9 \%)$ & $6(2.0 \%)$ & 9 (3.0\%) & \\
\hline
\end{tabular}

$3.1-6.0 h$

$>6.0 \mathrm{~h}$
$307 \quad 300$

$62.1(43.1 ; \quad 61.9(44.2 ; \quad 0.314$

79.7)

80.8)

$229(74.6 \%) \quad 206(68.7 \%) \quad 0.001$

Ischemic risk

stratification

High risk patients

$37(77.1 \%)$

$300(63.0 \%)$

$178(58.0 \%)$

$194(64.7 \%)$

0.046

\section{History}

Hyperlipidemia

$11(22.9 \%)$

159 (33.4\%)

118 (38.4\%)

$102(34.0 \%)$

0.157

$\mathrm{BMI} \geq 30$

7 (14.6\%)

$76(16.0 \%)$

59 (19.2\%)

$81(27.0 \%)$

0.002

Hypertension

$22(45.8 \%)$

234 (49.2\%)

$160(52.1 \%)$

168 (56.0\%)

0.247

Current smoker

$33(68.8 \%)$

308 (64.7\%)

$188(61.2 \%)$

196 (65.3\%)

0.621

STEMI, ST-segment-elevation myocardial infarction; LBBB, left bundle-branch block RBBB, right bundle-branch block; BMI, body mass index; $\mathrm{Ml}$, myocardial infarction; $\mathrm{PCl}$, percutaneous coronary intervention; CABG, coronary artery bypass grafting; TIMI, Thrombolysis in Myocardial Infarction; ACE Inhibitors, angiotensinconverting-enzyme inhibitors; ARB, angiotensin-receptor blocker; LVEF, left ventricular ejection fraction; GP, glycoprotein 


\begin{tabular}{|c|c|c|c|c|c|}
\hline & $\leq 1.0 \mathrm{~h}$ & $1.1-3.0 \mathrm{~h}$ & $3.1-6.0 h$ & $>6.0 \mathrm{~h}$ & \\
\hline Diabetes mellitus & $10(20.8 \%)$ & $86(18.1 \%)$ & $73(23.8 \%)$ & $65(21.7 \%)$ & 0.258 \\
\hline Previous MI & $4(8.3 \%)$ & $50(10.5 \%)$ & 19 (6.2\%) & 22 (7.3\%) & 0.166 \\
\hline Previous PCl & $2(4.2 \%)$ & $39(8.2 \%)$ & $22(7.2 \%)$ & $18(6.0 \%)$ & 0.652 \\
\hline Previous CABG & $0(0.0 \%)$ & $7(1.5 \%)$ & $6(2.0 \%)$ & $6(2.0 \%)$ & 0.912 \\
\hline Chronic heart failure & $0(0.0 \%)$ & $5(1.1 \%)$ & $2(0.7 \%)$ & $3(1.0 \%)$ & 0.903 \\
\hline Chronic renal failure & $1(2.1 \%)$ & $7(1.5 \%)$ & $4(1.3 \%)$ & $3(1.0 \%)$ & 0.790 \\
\hline $\begin{array}{l}\text { Peripheral arterial } \\
\text { disease }\end{array}$ & $1(2.1 \%)$ & $12(2.5 \%)$ & $10(3.3 \%)$ & $8(2.7 \%)$ & 0.934 \\
\hline \multicolumn{6}{|l|}{ Chronic therapy } \\
\hline Aspirin & $7(14.6 \%)$ & $68(14.3 \%)$ & 52 (16.9\%) & $49(16.3 \%)$ & 0.752 \\
\hline Beta-Blockers & $3(6.3 \%)$ & $82(17.2 \%)$ & $68(22.1 \%)$ & $59(19.7 \%)$ & 0.034 \\
\hline ACE Inhibitors & $4(8.3 \%)$ & 99 (20.8\%) & $68(22.1 \%)$ & $90(30.0 \%)$ & 0.001 \\
\hline ARB & $6(12.5 \%)$ & $47(9.9 \%)$ & $42(13.7 \%)$ & 31 (10.3\%) & 0.373 \\
\hline Statins & $4(8.3 \%)$ & 78 (16.4\%) & 57 (18.6\%) & $66(22.0 \%)$ & 0.067 \\
\hline $\begin{array}{l}\text { Proton Pump } \\
\text { Inhibitors }\end{array}$ & $0(0.0 \%)$ & $29(6.1 \%)$ & $23(7.5 \%)$ & $21(7.0 \%)$ & 0.209 \\
\hline \multicolumn{6}{|l|}{ Procedure } \\
\hline Pre-TIMI flow < 2 & $28(58.3 \%)$ & $287(60.5 \%)$ & 198 (64.9\%) & $201(67.2 \%)$ & 0.220 \\
\hline Post-procedural & $1(2.1 \%)$ & $13(2.7 \%)$ & $18(5.9 \%)$ & $22(7.4 \%)$ & 0.015 \\
\hline \multicolumn{6}{|l|}{ TIMI flow $<3$} \\
\hline $\begin{array}{l}\text { Number of diseased } \\
\text { vessels }>1\end{array}$ & $26(54.2 \%)$ & $220(46.3 \%)$ & $149(48.7 \%)$ & $176(58.7 \%)$ & 0.007 \\
\hline Stem disease & $2(4.2 \%)$ & $12(2.5 \%)$ & $8(2.6 \%)$ & $17(5.7 \%)$ & 0.092 \\
\hline \multicolumn{6}{|l|}{ unsuccessful PCI } \\
\hline $\begin{array}{l}\text { STEMI, ST-segment-e } \\
\text { bundle-branch block; } \\
\text { intervention; CABG, cc } \\
\text { Inhibitors, angiotensi } \\
\text { ventricular ejection fr }\end{array}$ & $\begin{array}{l}\text { nyocardial ir } \\
\text { y mass inde) } \\
\text { rtery bypass } \\
\text { ng-enzyme ir } \\
\text {, glycoprotei }\end{array}$ & $\begin{array}{l}\text { ction; LBBB, I } \\
\text { II, myocardial } \\
\text { fting; TIMI, Tr } \\
\text { oitors; ARB, an }\end{array}$ & $\begin{array}{l}\text { bundle-branch } \\
\text { arction; PCl, p€ } \\
\text { mbolysis in M } \\
\text { tensin-receptc }\end{array}$ & $\begin{array}{l}\text { lock RBBB, ric } \\
\text { utaneous cor } \\
\text { cardial Infarc } \\
\text { olocker; LVEF, }\end{array}$ & aCE \\
\hline
\end{tabular}




\begin{tabular}{|c|c|c|c|c|c|}
\hline & $\leq 1.0 \mathrm{~h}$ & $1.1-3.0 h$ & $3.1-6.0 h$ & $>6.0 \mathrm{~h}$ & \\
\hline Only PTCA & $1(2.1 \%)$ & $16(3.4 \%)$ & $8(2.6 \%)$ & $19(6.4 \%)$ & \multirow[t]{2}{*}{0.100} \\
\hline Stent & 47 (97.9\%) & $458(96.6 \%)$ & $296(97.4 \%)$ & $280(93.6 \%)$ & \\
\hline \multicolumn{5}{|l|}{ thrombectomy } & 0.001 \\
\hline Bare-metal stent & $12(25.5 \%)$ & $107(23.4 \%)$ & $89(30.1 \%)$ & $92(32.9 \%)$ & 0.029 \\
\hline Drug-eluting stent & $32(68.1 \%)$ & $329(71.8 \%)$ & $192(64.9 \%)$ & $172(61.4 \%)$ & 0.023 \\
\hline \multicolumn{5}{|l|}{ ascular scaffold } & 0.729 \\
\hline \multicolumn{6}{|l|}{$\begin{array}{l}\text { Antitrombotic } \\
\text { therapy }\end{array}$} \\
\hline Aspirin & $46(95.8 \%)$ & $466(97.9 \%)$ & $296(96.4 \%)$ & $288(96.0 \%)$ & 0.318 \\
\hline Prasugrel & $23(47.9 \%)$ & $239(50.2 \%)$ & $160(52.1 \%)$ & $162(54.0 \%)$ & \multirow[t]{2}{*}{0.717} \\
\hline Ticagrelor & $25(52.1 \%)$ & $237(49.8 \%)$ & $147(47.9 \%)$ & $138(46.0 \%)$ & \\
\hline $\begin{array}{l}\text { Unfractionated } \\
\text { heparin }\end{array}$ & $46(95.8 \%)$ & $463(97.3 \%)$ & $296(96.4 \%)$ & $283(94.3 \%)$ & 0.199 \\
\hline Enoxaparine & $4(8.3 \%)$ & $41(8.6 \%)$ & $42(13.7 \%)$ & $32(10.7 \%)$ & 0.160 \\
\hline Fondaparinux & $0(0.0 \%)$ & $8(1.7 \%)$ & $6(2.0 \%)$ & $8(2.7 \%)$ & 0.703 \\
\hline \multicolumn{5}{|l|}{ bailout therapy } & 0.728 \\
\hline LV EF \% & $\begin{array}{l}45.0(25.0 ; \\
65.0)\end{array}$ & $\begin{array}{l}50.0(32.0 \\
65.0)\end{array}$ & $\begin{array}{l}50.0(30.0 \\
65.0)\end{array}$ & $\begin{array}{l}48.5(35.0 ; \\
65.0)\end{array}$ & 0.365 \\
\hline $\begin{array}{l}\text { STEMI, ST-segment- } \\
\text { bundle-branch block } \\
\text { intervention; CABG, } \\
\text { Inhibitors, angiotens } \\
\text { ventricular ejection }\end{array}$ & $\begin{array}{l}\text { nyocardial } \\
\text { y mass ind } \\
\text { tery bypas } \\
\text { ig-enzyme } \\
\text {, glycopro }\end{array}$ & $\begin{array}{l}\text { ction; LBBB, } \\
\text { I, myocardia } \\
\text { fting; TIMI, } \\
\text { itors; ARB, a }\end{array}$ & $\begin{array}{l}\text { undle-branc } \\
\text { rction; PCI, } \\
\text { nbolysis in } 1 \\
\text { tensin-recep }\end{array}$ & $\begin{array}{l}\text { lock RBBB, r } \\
\text { cutaneous co } \\
\text { cardial Infar } \\
\text { blocker; LVEF }\end{array}$ & $\begin{array}{l}\text { ary } \\
\text { n; } A C E\end{array}$ \\
\hline
\end{tabular}

Notably, the highest incidence of the combined ischemic endpoint was observed in patients with SNTs $\leq$ 1 hour compared to the patient groups with SNTs 1.1-3.0 hours, 3.1-6.0 hours, and $>6$ hours both at 30 days $(10.4 \%$ vs. $3.4 \%, 2.0 \%$, and $2.3 \%, p=0.032)$, and 1 year $(16.7 \%$ vs. $4.8 \%, 4.6 \%$, and $7.3 \%, p=0.011)$ (Table 2, Fig. 1). 
Table 2

Endpoints and intervals from symptoms onset to coronary angiography

Symptom onset to needle time (hours)

P-value

$\leq 1.0 h \quad 1.1-3.0 h \quad 3.1-6.0 h \quad>6.0 h$

30 days

\begin{tabular}{|llllll|}
\hline Death from any cause & $4(8.3 \%)$ & $11(2.3 \%)$ & $5(1.6 \%)$ & $6(2.0 \%)$ & 0.077 \\
\hline Cardiovascular death & $3(6.3 \%)$ & $10(2.1 \%)$ & $2(0.7 \%)$ & $5(1.7 \%)$ & 0.055 \\
\hline Re-MI & $3(6.3 \%)$ & $5(1.1 \%)$ & $4(1.3 \%)$ & $2(0.7 \%)$ & 0.053 \\
\hline Re-MI | periPCI MI & $3(6.3 \%)$ & $15(3.2 \%)$ & $15(4.9 \%)$ & $7(2.3 \%)$ & 0.194 \\
\hline Stroke & $1(2.1 \%)$ & $2(0.4 \%)$ & $0(0.0 \%)$ & $0(0.0 \%)$ & 0.103 \\
\hline Cardiovascular death | Re-MI IStroke & $5(10.4 \%)$ & $16(3.4 \%)$ & $6(2.0 \%)$ & $7(2.3 \%)$ & 0.032 \\
\hline Stent thrombosis & $2(4.2 \%)$ & $4(0.8 \%)$ & $2(0.7 \%)$ & $2(0.7 \%)$ & 0.176 \\
\hline 365 days & & & & & \\
\hline Death from any cause & $7(14.6 \%)$ & $17(3.6 \%)$ & $9(2.9 \%)$ & $14(4.7 \%)$ & 0.010 \\
\hline Cardiovascular death & $5(10.4 \%)$ & $13(2.7 \%)$ & $5(1.6 \%)$ & $10(3.3 \%)$ & 0.024 \\
\hline Re-MI & $4(8.3 \%)$ & $8(1.7 \%)$ & $8(2.6 \%)$ & $11(3.7 \%)$ & 0.042 \\
\hline Re-MI | periPCI MI & $4(8.3 \%)$ & $18(3.8 \%)$ & $19(6.2 \%)$ & $16(5.3 \%)$ & 0.249 \\
\hline Stroke & $1(2.1 \%)$ & $3(0.6 \%)$ & $3(1.0 \%)$ & $2(0.7 \%)$ & 0.516 \\
\hline Cardiovascular death | Re-MI IStroke & $8(16.7 \%)$ & $23(4.8 \%)$ & $14(4.6 \%)$ & $22(7.3 \%)$ & 0.011 \\
\hline Stent thrombosis & $2(4.2 \%)$ & $5(1.1 \%)$ & $3(1.0 \%)$ & $6(2.0 \%)$ & 0.205 \\
\hline Ml, myocardial infarction; PCl, percutaneous coronary intervention & & \\
\hline
\end{tabular}

Also, the al-cause mortality, cardiovascular mortality, and incidence of recurrent MI were more frequent in the SNT $\leq 1$ hour group of patients at 1 year. However, patients with SNT $\leq 1$ hour were in $22.9 \%$ cardiogenic shock (Killip IV) patients, compared to only $2.9 \%, 2.0 \%$, and $3.0 \%$ in groups $1.1-3.0$ hours, 3.16.0 hours, and $>6$ hours $(p<0.001)$. The combined prevalence of resuscitation/out-of-hospital cardiac arrest (OHCA)/cardiogenic shock was $41.7 \%(\mathrm{~N}=20)$ for the SNT $\leq 1$ hour group. If these patients were excluded to avoid bias, no significant difference in the occurrence of any ischemic endpoint was found between the other SNT groups $(p=0.177)$.

\section{High-risk vs. low-risk groups}

Admission stratification relative to ischemic risk (according to the abovementioned TIMI criteria) revealed $62.7 \%(N=709)$ high-risk patients and $37.2 \%(N=422)$ low-risk patients. The proportion of high-risk 
patients in the SNT $<1$ hour group $(77.1 \%)$ was significantly higher than in the patient groups with SNTs 1.1-3.0 hours, 3.1-6.0 hours, and $>6$ hours $(p=0.046)$.

High-risk patients had a higher incidence of all-cause death, cardiovascular death, and combined ischemic endpoint both at 30 days $(3.4 \%$ vs. $0.5 \%, p=0.001$, and $2.5 \%$ vs. $0.5 \%, p=0.010$, and $3.8 \%$ vs. $1.7 \%, p=0.047)$ and at 1 year $(6.1 \%$ vs. $0.9 \%, p<0.001$, and $4.1 \%$ vs. $0.9 \%, p=0.002$, and $7.5 \%$ vs. $3.3 \%, p$ $=0.004$ ), irrespective of SNT duration (Table S1 in Supplementary material). Symptom-to-needle time analysis with a cut-off of 4 hours revealed that SNT $>4$ hours in high-risk vs. low-risk patients was associated with more frequent all-cause death [OR (95\% Cl) $5.15(1.17-22.70) p=0.030]$, recurrent AMI [OR $(95 \% \mathrm{Cl}) 3.23(1.09-9.62) \mathrm{p}=0.035$ ], and a higher incidence of the combined ischemic endpoint [OR $(95 \% \mathrm{Cl}) 2.83(1.14-7.03) \mathrm{p}=0.025$ ] at 1 year (Fig. 1). For the high-risk patient group only, a comparison of "late comers" vs. "early comers" found a higher incidence of MI within one year $(p=0.043)$ for "late comers." For the low-risk group, no differences in the incidence of ischemic outcomes were found.

\section{Cardiogenic shock}

Cardiogenic shock was present at admission in $3.5 \%$ of patients $(\mathrm{N}=40)$. The 30 -day mortality of patients with cardiogenic shock was $25 \%$ vs. $1.5 \%$ in patients with Killip I-III $(p<0.001)$, and the 1-year mortality was $40 \%$ vs. $2.8 \%$ ( $p<0.001)$. Mortality and the incidence of combined ischemic endpoints were similar across the spectrum of patients categorized according to SNT groups. Thus, the SNT interval alone did not affect mortality of patients presenting in cardiogenic shock; however, the percentage of patients with cardiogenic shock was the highest in the SNT $\leq 1$ hour group. (described in detail above) (Table 3). 
Table 3

Endpoints and intervals from symptoms onset to coronary angiography in patients with Killip =4; $N=40$

Symptom onset to needle time (hours)

P-value

$\leq 1.0 h \quad 1.1-3.0 h \quad 3.1-6.0 h \quad>6.0 h$

30 days

\begin{tabular}{|llllll|}
\hline Death from any cause & $2(18.2 \%)$ & $3(21.4 \%)$ & $2(33.3 \%)$ & $3(33.3 \%)$ & 0.786 \\
\hline Cardiovascular death & $2(18.2 \%)$ & $3(21.4 \%)$ & $1(16.7 \%)$ & $2(22.2 \%)$ & 0.999 \\
\hline Re-MI & $1(9.1 \%)$ & $0(0.0 \%)$ & $1(16.7 \%)$ & $0(0.0 \%)$ & 0.290 \\
\hline Re-MI | periPCI MI & $1(9.1 \%)$ & $0(0.0 \%)$ & $1(16.7 \%)$ & $1(11.1 \%)$ & 0.428 \\
\hline Stroke & $0(0.0 \%)$ & $0(0.0 \%)$ & $0(0.0 \%)$ & $0(0.0 \%)$ & - \\
\hline Cardiovascular death | Re-MI IStroke & $2(18.2 \%)$ & $3(21.4 \%)$ & $2(33.3 \%)$ & $2(22.2 \%)$ & 0.909 \\
\hline Stent thrombosis & $1(9.1 \%)$ & $1(7.1 \%)$ & $0(0.0 \%)$ & $0(0.0 \%)$ & 0.999 \\
\hline 365 days & & & & & \\
\hline Death from any cause & $5(45.5 \%)$ & $5(35.7 \%)$ & $2(33.3 \%)$ & $4(44.4 \%)$ & 0.970 \\
\hline Cardiovascular death & $4(36.4 \%)$ & $5(35.7 \%)$ & $1(16.7 \%)$ & $3(33.3 \%)$ & 0.901 \\
\hline Re-MI & $2(18.2 \%)$ & $0(0.0 \%)$ & $1(16.7 \%)$ & $0(0.0 \%)$ & 0.134 \\
\hline Re-MI | periPCl MI & $2(18.2 \%)$ & $0(0.0 \%)$ & $1(16.7 \%)$ & $1(11.1 \%)$ & 0.301 \\
\hline Stroke & $0(0.0 \%)$ & $0(0.0 \%)$ & $0(0.0 \%)$ & $0(0.0 \%)$ & - \\
\hline Cardiovascular death | Re-MI |Stroke & $5(45.5 \%)$ & $5(35.7 \%)$ & $2(33.3 \%)$ & $3(33.3 \%)$ & 0.938 \\
\hline Stent thrombosis & $1(9.1 \%)$ & $1(7.1 \%)$ & $0(0.0 \%)$ & $0(0.0 \%)$ & 0.999 \\
\hline Ml, myocardial infarction; PCl, percutaneous coronary intervention & & \\
\hline
\end{tabular}

\section{Discussion}

Our study found, based on patient medical histories and characteristics, that the most significant factor related to a longer SNT was gender. A possible cause and explanation of longer SNTs in women may be the more frequent occurrence of atypical symptoms, resulting in significant delays from symptom onset to contacting the emergency system $[18,19]$. Women often have no chest pain [20] or consider the pain to be insignificant or not life-threatening [21]. In the VIRGO study (Variation in Recovery: Role of Gender on Outcomes of Young AMI Patients), only half of patients $<55$ years of age presenting with an acute myocardial infarction considered themselves at risk for heart disease before their event, despite having several cardiac risk factors [19]. Women were less likely than men to be told by their physician that they were at risk of cardiovascular disease or to have conversations about risk reduction. 
Significantly longer SNTs were found in patients treated for arterial hypertension and in obese females, but not males. These findings are consistent with previous studies [22-24].

A negative trend toward longer delays (thus not statistically significant) was observed in patients with a history of CABG, and in diabetic patients while a trend toward shorter delay was seen in patients with a history of prior Ml. Prolongation of time delay in diabetic patients has been consistently reported across studies, and related to atypical signs and symptoms of $\mathrm{MI}$ in this population [25-27]. Studies investigating pre-hospital delay in patients with prior CABG or MI reported conflicting results of whether patients with these comorbidities present earlier or not. In The Worcester Heart Attack Study, the researchers found that previous MI was associated with longer delays [27], other investigators $[25,26,28,29]$ reported significantly shorter pre-hospital delays in these patients. In a prospective cohort study performed by Coventry et al. the patients with previous $\mathrm{Ml}$ had shorter time delay than patients without previous $\mathrm{MI}$ or $\mathrm{CABG}$, but patients with previous $\mathrm{MI}$ and $\mathrm{CABG}$ compared with previous $\mathrm{MI}$ alone had longer time delays [30]. The probable reason for these findings is that some patients perceive seriousness of the disease and potential threat after the first event while others think it is not likely to have a second MI after a successful CABG operation. Moreover, socio-demographic factors (e.g. marital status), cognitive (higher educational level [28,31]) and behavioral factors play a role when deciding to call emergency system or come to a hospital to seek help [32]. There is limited evidence that community media-based Ml-awareness campaigns lead to shortening time delays [30,33], therefore a face-to-face educational intervention in selected high-risk patients (post MI/CABG, with diabetes) was proposed to be more beneficial. Despite the fact that a randomized trial conducted by Dracup et al [34] failed to prove this concept, the MEDEA study demonstrated that patients with a knowledge of MI symptoms and treatment presented with shorter time delays [35]. Thus, continuous efforts need to be taken to educate high risk patients to further reduce pre-hospital delay.

In the patients with longer SNTs, there was a higher incidence of post-PCI suboptimal TIMI flow in the culprit vessel despite the fact, that all patients were given appropriate combined antithrombotic therapy including prasugrel or ticagrelor at a cathlab prior to revascularization. Our results are consistent with previous reports that found a positive correlation between shorter time delays and more favorable postprocedural findings on the infarct-related artery [36,37]. In the ATLANTIC (Administration of Ticagrelor in the Cath Lab or in the Ambulance for New ST Elevation Myocardial Infarction to Open the Coronary Artery) study, early (pre-hospital) compared to in-hospital administration of ticagrelor in STEMI patients did not result in more frequent TIMI 3 flow prior to and post- $\mathrm{PCl}$ but reduced stent thrombosis rates, irrespective of initial TIMI risk score of the patients [38]. To sum up, the data suggest that affecting time delay is of higher importance than timing of the first (loading) dose of a potent P2Y12 inhibitor, as long as given prior to $\mathrm{PCl}$.

The study found only a borderline relationship between longer SNTs (i.e., above the median value) and the occurrence of the composite ischemic endpoint when no risk stratification was applied. Despite a low incidence of endpoints both at 30 days and 1 year, the present data demonstrated that stratification of patients at admission, relative to ischemic risk using the TIMI Risk Score (including hemodynamic 
parameters, disease-specific patient medical history, and age) is still the most important act the attending clinician must perform, and in high-risk patients to subsequently take actions in order to maximally shorten time delay to reperfusion. Such approach, together with the use of potent antiplatelet therapy including prasugrel or ticagrelor, resulted in a better survival and less ischemic events. In patients with a low-risk profile at admission, with the same antiplatelet therapy applied, the prognostic effect of short time delay was not pronounced.

Similarly to previous publications [39,40], the majority of cardiogenic shock patients enrolled in our study arrived early (SNT $\leq 1$ hour) after the onset of symptoms but still having the worst prognosis. These patients arrived in very poor condition, had been resuscitated, and on hemodynamic or ventilator support. The poor outcomes in these cases were likely determined before the patient ever reached a Cath lab and were independent of elapsed SNT.

\section{Limitations}

The study has specific limitations. Compared to some other studies, the sample size was relatively small. Moreover, it is important to note that number of patients in the group with SNT $\leq 1$ hour was markedly lower compared to the numbers in the other groups. However, it was a multicenter, investigator-initiated study in which data collection was closely monitored and endpoints confirmed by an adjudication committee. The statistical power of our analyses was reduced due to the small number of endpoints in the Prague 18 study. Due to regional health care differences, the results from this study may not be entirely comparable with STEMI management used in other countries.

\section{Conclusion}

In this study of patients referred to primary PCI and treated with prasugrel or ticagrelor, longer SNTs were associated with more frequent suboptimal PCI results. Stratification of patients based on their initial ischemic risk proved to have more prognostic power than SNT. Longer time delay only in high risk patients significantly increased the incidence of ischemic events and all-cause mortality, compared to low risk patients.

\section{Abbreviations}

AMI- acute myocardial infarction

CABG - coronary artery bypass grafting

LBBB - left bundle-branch block

OHCA - out-of-hospital cardiac arrest

SNT - symptoms onset to needle time 
$\mathrm{PCl}$ - primary percutaneous coronary intervention

STEMI - ST elevations acute myocardial infarction

TIMI - Thrombolysis In Myocardial Infarction

\section{Declarations}

\section{CONSENT TO PARTICIPATE}

Patients signed informed consent to participate in the clinical study.

\section{CONSENT TO PUBLISH}

All authors agree with the publication.

\section{ETHICAL APPROVAL AND INFORMED CONSENT}

The study was conducted with approval of the trial design and protocol by the Ethics Committee for Multicenter Clinical Trials, University Hospital Kralovske Vinohrady, Prague, Czech Republic, and the local ethics committees at each participating site. The study conformed to the principles of the Declaration of Helsinki. Patients signed informed consent to participate in the clinical study.

\section{DATA AVAILABILITY}

Raw data available on request.

\section{COMPETING INTERESTS}

Dr. Motovska reports receiving speaking and advisory board fees from AstraZeneca and Eli Lilly. Dr Varvarovsky reports receiving honoraria form AstraZeneca and Eli Lilly. Dr. Rokyta reports receiving lecture fees from AstraZeneca. Dr.Widimsky reports receiving honoraria from AstraZeneca, Eli Lilly, and Daiichi Sankyo. The other authors report no conflicts.

\section{FUNDING}

This work was supported by the Charles University Cardiovascular Research Program P-35 and Q-38, Charles University, Czech Republic. 


\section{AUTHORS' CONTRIBUTIONS}

Z.M. had the original idea for the Prague-18 study. M.H., Z.M., O.H., P.K., I.V., J.D., F.T., P.J., S.S., M.B., J.M., R.M., R.R., P.W. were investigators, M.H., Z.M. designed the time delay substudy, M.H., Z.M. prepared the manuscript. J.J., M.S. analysed the data. Figures and Tables were created by J.J., M.S.

\section{ACKNOWLEDGMENTS}

The authors of the manuscript express their thanks to the doctors and nurses in the study centres who have cooperated on the project and contributed to obtaining clinical and laboratory data. The authors thank Mr. Thomas Secrest (Secrest Editing, Inc.) for the English editing.

\section{References}

1. Eagle KA, Lim MJ, Dabbous OH, Pieper KS, Goldberg RJ, Van de Werf F, et al. A validated prediction model for all forms of acute coronary syndrome: estimating the risk of 6-month postdischarge death in an international registry. JAMA. 2004;291:2727-33. https://doi.org/10.1001/jama.291.22.2727.

2. Addala S, Grines CL, Dixon SR, Stone GW, Boura JA, Ochoa AB, et al. Predicting mortality in patients with ST-elevation myocardial infarction treated with primary percutaneous coronary intervention (PAMI risk score). Am J Cardiol. 2004;93:629-32. https://doi.org/10.1016/j.amjcard.2003.11.036.

3. Amin Sameer T, Morrow David A, Eugene B, Sarah S, Charles C, Sabina M, et al. Dynamic TIMI Risk Score for STEMI. Journal of the American Heart Association n.d.;2:e003269. https://doi.org/10.1161/JAHA.112.003269.

4. De Luca G, Suryapranata H, van 't Hof AWJ, de Boer M-J, Hoorntje JCA, Dambrink J-HE, et al. Prognostic assessment of patients with acute myocardial infarction treated with primary angioplasty: implications for early discharge. Circulation. 2004;109:2737-43. https://doi.org/10.1161/01.CIR.0000131765.73959.87.

5. Halkin A, Singh M, Nikolsky E, Grines CL, Tcheng JE, Garcia E, et al. Prediction of mortality after primary percutaneous coronary intervention for acute myocardial infarction: the CADILLAC risk score. J Am Coll Cardiol. 2005;45:1397-405. https://doi.org/10.1016/j.jacc.2005.01.041.

6. Fox KAA, Dabbous OH, Goldberg RJ, Pieper KS, Eagle KA, Van de Werf F, et al. Prediction of risk of death and myocardial infarction in the six months after presentation with acute coronary syndrome: prospective multinational observational study (GRACE). BMJ. 2006;333:1091. https://doi.org/10.1136/bmj.38985.646481.55.

7. Terkelsen CJ. System Delay and Mortality Among Patients With STEMI Treated With Primary Percutaneous Coronary Intervention. JAMA. 2010;304:763. https://doi.org/10.1001/jama.2010.1139.

8. Fordyce CB, Al-Khalidi HR, Jollis JG, Roettig ML, Gu J, Bagai A, et al. Association of Rapid Care Process Implementation on Reperfusion Times Across Multiple ST-Segment-Elevation Myocardial 
Infarction Networks. Circ Cardiovasc Interv 2017;10.

https://doi.org/10.1161/CIRCINTERVENTIONS.116.004061.

9. Ibanez B, James S, Agewall S, Antunes MJ, Bucciarelli-Ducci C, Bueno H, et al. 2017 ESC Guidelines for the management of acute myocardial infarction in patients presenting with ST-segment elevation. Eur Heart J. 2017;2018:119-77. https://doi.org/10.1093/eurheartj/ehx393.

10. Nallamothu BK, Bradley EH, Krumholz HM. Time to Treatment in Primary Percutaneous Coronary Intervention. N Engl J Med. 2007;357:1631-8. https://doi.org/10.1056/NEJMra065985.

11. Bagai A, Jollis JG, Dauerman HL, Peng SA, Rokos IC, Bates ER, et al. Emergency department bypass for ST-Segment-elevation myocardial infarction patients identified with a prehospital electrocardiogram: a report from the American Heart Association Mission: Lifeline program. Circulation. 2013;128:352-9. https://doi.org/10.1161/CIRCULATIONAHA.113.002339.

12. Swaminathan RV, Wang TY, Kaltenbach LA, Kim LK, Minutello RM, Bergman G, et al. Nonsystem reasons for delay in door-to-balloon time and associated in-hospital mortality: a report from the National Cardiovascular Data Registry. J Am Coll Cardiol. 2013;61:1688-95. https://doi.org/10.1016/j.jacc.2012.11.073.

13. Rathore SS, Curtis JP, Chen J, Wang Y, Nallamothu BK, Epstein AJ, et al. Association of door-toballoon time and mortality in patients admitted to hospital with ST elevation myocardial infarction: national cohort study. BMJ. 2009;338:b1807. https://doi.org/10.1136/bmj.b1807.

14. Shiomi H, Nakagawa Y, Morimoto T, Furukawa Y, Nakano A, Shirai S, et al. Association of onset to balloon and door to balloon time with long term clinical outcome in patients with ST elevation acute myocardial infarction having primary percutaneous coronary intervention: observational study. BMJ. 2012;344:e3257. https://doi.org/10.1136/bmj.e3257.

15. Motovska Z, Hlinomaz O, Miklik R, Hromadka M, Varvarovsky I, Dusek J, et al. Prasugrel Versus Ticagrelor in Patients With Acute Myocardial Infarction Treated With Primary Percutaneous Coronary Intervention: Multicenter Randomized PRAGUE-18 Study. Circulation. 2016;134:1603-12. https://doi.org/10.1161/CIRCULATIONAHA.116.024823.

16. Motovska Z, Hlinomaz O, Kala P, Hromadka M, Knot J, Varvarovsky I, et al. 1-Year Outcomes of Patients Undergoing Primary Angioplasty for Myocardial Infarction Treated With Prasugrel Versus Ticagrelor. J Am Coll Cardiol. 2018;71:371-81. https://doi.org/10.1016/j.jacc.2017.11.008.

17. Morrow DA, Antman EM, Charlesworth A, Cairns R, Murphy SA, de Lemos JA, et al. TIMI risk score for ST-elevation myocardial infarction: A convenient, bedside, clinical score for risk assessment at presentation: An intravenous nPA for treatment of infarcting myocardium early II trial substudy. Circulation. 2000;102:2031-7. https://doi.org/10.1161/01.cir.102.17.2031.

18. Meyer MR, Bernheim AM, Kurz DJ, O'Sullivan CJ, Tüller D, Zbinden R, et al. Gender differences in patient and system delay for primary percutaneous coronary intervention: current trends in a Swiss ST-segment elevation myocardial infarction population. Eur Heart J Acute Cardiovasc Care. 2019;8:283-90. https://doi.org/10.1177/2048872618810410. 
19. D’Onofrio G, Safdar B, Lichtman JH, Strait KM, Dreyer RP, Geda M, et al. Sex differences in reperfusion in young patients with ST-segment-elevation myocardial infarction: results from the VIRGO study. Circulation. 2015;131:1324-32.

https://doi.org/10.1161/CIRCULATIONAHA.114.012293.

20. Khan NA, Daskalopoulou SS, Karp I, Eisenberg MJ, Pelletier R, Tsadok MA, et al. Sex differences in acute coronary syndrome symptom presentation in young patients. JAMA Intern Med. 2013;173:1863-71. https://doi.org/10.1001/jamainternmed.2013.10149.

21. Leslie WS, Urie A, Hooper J, Morrison CE. Delay in calling for help during myocardial infarction: reasons for the delay and subsequent pattern of accessing care. Heart. 2000;84:137-41. https://doi.org/10.1136/heart.84.2.137.

22. Das SR, Alexander KP, Chen AY, Powell-Wiley TM, Diercks DB, Peterson ED, et al. Impact of body weight and extreme obesity on the presentation, treatment, and in-hospital outcomes of 50,149 patients with ST-Segment elevation myocardial infarction results from the NCDR (National Cardiovascular Data Registry). J Am Coll Cardiol. 2011;58:2642-50. https://doi.org/10.1016/j.jacc.2011.09.030.

23. Tiffany C-L, Junghyun K, Bower Julie K, Angela G, Raymond F, Obesity LJamesR. Treatment Times, and Cardiovascular Outcomes After ST-Elevation Myocardial Infarction: Findings From Mission: Lifeline North Texas. Journal of the American Heart Association n.d.;6:e005827. https://doi.org/10.1161/JAHA.117.005827.

24. De Luca G, Dirksen MT, Spaulding C, Kelbæk H, Schalij M, Thuesen L, et al. Impact of hypertension on clinical outcome in STEMI patients undergoing primary angioplasty with BMS or DES: insights from the DESERT cooperation. Int J Cardiol. 2014;175:50-4. https://doi.org/10.1016/j.ijcard.2014.04.180.

25. Ting HH, Bradley EH, Wang Y, Lichtman JH, Nallamothu BK, Sullivan MD, et al. Factors Associated With Longer Time From Symptom Onset to Hospital Presentation for Patients With ST-Elevation Myocardial Infarction. Arch Intern Med. 2008;168:959-68. https://doi.org/10.1001/archinte.168.9.959.

26. Gibler WB, Armstrong PW, Ohman EM, Weaver WD, Stebbins AL, Gore JM, et al. Persistence of delays in presentation and treatment for patients with acute myocardial infarction: The GUSTO-I and GUSTO-III experience. Ann Emerg Med. 2002;39:123-30.

https://doi.org/10.1067/mem.2002.121402.

27. Saczynski JS, Yarzebski J, Lessard D, Spencer FA, Gurwitz JH, Gore JM, et al. Trends in Prehospital Delay in Patients With Acute Myocardial Infarction (from the Worcester Heart Attack Study). The American Journal of Cardiology. 2008;102:1589-94. https://doi.org/10.1016/j.amjcard.2008.07.056.

28. Peng YG, Feng JJ, Guo LF, Li N, Liu WH, Li GJ, et al. Factors associated with prehospital delay in patients with ST-segment elevation acute myocardial infarction in China. The American Journal of Emergency Medicine. 2014;32:349-55. https://doi.org/10.1016/j.ajem.2013.12.053. 
29. Sheifer SE, Rathore SS, Gersh BJ, Weinfurt KP, Oetgen WJ, Breall JA, et al. Time to presentation with acute myocardial infarction in the elderly: associations with race, sex, and socioeconomic characteristics. Circulation. 2000;102:1651-6. https://doi.org/10.1161/01.cir.102.14.1651.

30. Coventry LL, Bremner AP, van Schalkwyk JW, Hegney DG, Thompson PL. The Effect of Media Campaigns, Patient Characteristics, and Presenting Symptoms on Prehospital Delay in Myocardial Infarction Patients: A Prospective Cohort Study. Heart Lung Circ. 2019;28:1161-75. https://doi.org/10.1016/j.hlc.2018.05.203.

31. Heo JY, Hong KJ, Shin SD, Song KJ, Ro YS. Association of educational level with delay of prehospital care before reperfusion in STEMI. Am J Emerg Med. 2015;33:1760-9. https://doi.org/10.1016/j.ajem.2015.08.019.

32. Khraim FM, Carey MG. Predictors of pre-hospital delay among patients with acute myocardial infarction. Patient Educ Couns. 2009;75:155-61. https://doi.org/10.1016/j.pec.2008.09.019.

33. Bray Janet E, Dion S, Philip N, Susie C, Lahn S, Michelle S, et al. Mass Media Campaigns' Influence on Prehospital Behavior for Acute Coronary Syndromes: An Evaluation of the Australian Heart Foundation's Warning Signs Campaign. Journal of the American Heart Association n.d.;4:e001927. https://doi.org/10.1161/JAHA.115.001927.

34. Dracup K, McKinley S, Riegel B, Moser DK, Meischke H, Doering LV, et al. A Randomized Clinical Trial to Reduce Patient Prehospital Delay to Treatment in Acute Coronary Syndrome. Circ Cardiovasc Qual Outcomes. 2009;2:524-32. https://doi.org/10.1161/CIRCOUTCOMES.109.852608.

35. Albarqouni L, Smenes K, Meinertz T, Schunkert H, Fang X, Ronel J, et al. Patients' knowledge about symptoms and adequate behaviour during acute myocardial infarction and its impact on delay time: Findings from the multicentre MEDEA Study. Patient Educ Couns. 2016;99:1845-51. https://doi.org/10.1016/j.pec.2016.06.007.

36. Maeng M, Nielsen PH, Busk M, Mortensen LS, Kristensen SD, Nielsen TT, et al. Time to treatment and three-year mortality after primary percutaneous coronary intervention for ST-segment elevation myocardial infarction-a DANish Trial in Acute Myocardial Infarction-2 (DANAMI-2) substudy. Am J Cardiol. 2010;105:1528-34. https://doi.org/10.1016/j.amjcard.2010.01.005.

37. Tarantini G, Cacciavillani L, Corbetti F, Ramondo A, Marra MP, Bacchiega E, et al. Duration of ischemia is a major determinant of transmurality and severe microvascular obstruction after primary angioplasty: a study performed with contrast-enhanced magnetic resonance. J Am Coll Cardiol. 2005;46:1229-35. https://doi.org/10.1016/j.jacc.2005.06.054.

38. Montalescot G, van 't Hof AW, Lapostolle F, Silvain J, Lassen JF, Bolognese L, et al. Prehospital Ticagrelor in ST-Segment Elevation Myocardial Infarction. N Engl J Med. 2014;371:1016-27. https://doi.org/10.1056/NEJMoa1407024.

39. Lee SH, Kim HK, Jeong MH, Lee JM, Gwon H-C, Chae SC, et al. Pre-hospital delay and emergency medical services in acute myocardial infarction. Korean J Intern Med. 2020;35:119-32. https://doi.org/10.3904/kjim.2019.123. 
40. Jäger B, Farhan S, Rohla M, Christ G, Podczeck-Schweighofer A, Schreiber W, et al. Clinical predictors of patient related delay in the VIENNA ST-elevation myocardial infarction network and impact on long-term mortality. Eur Heart J Acute Cardiovasc Care. 2017;6:254-61. https://doi.org/10.1177/2048872616633882.

\section{Figures}
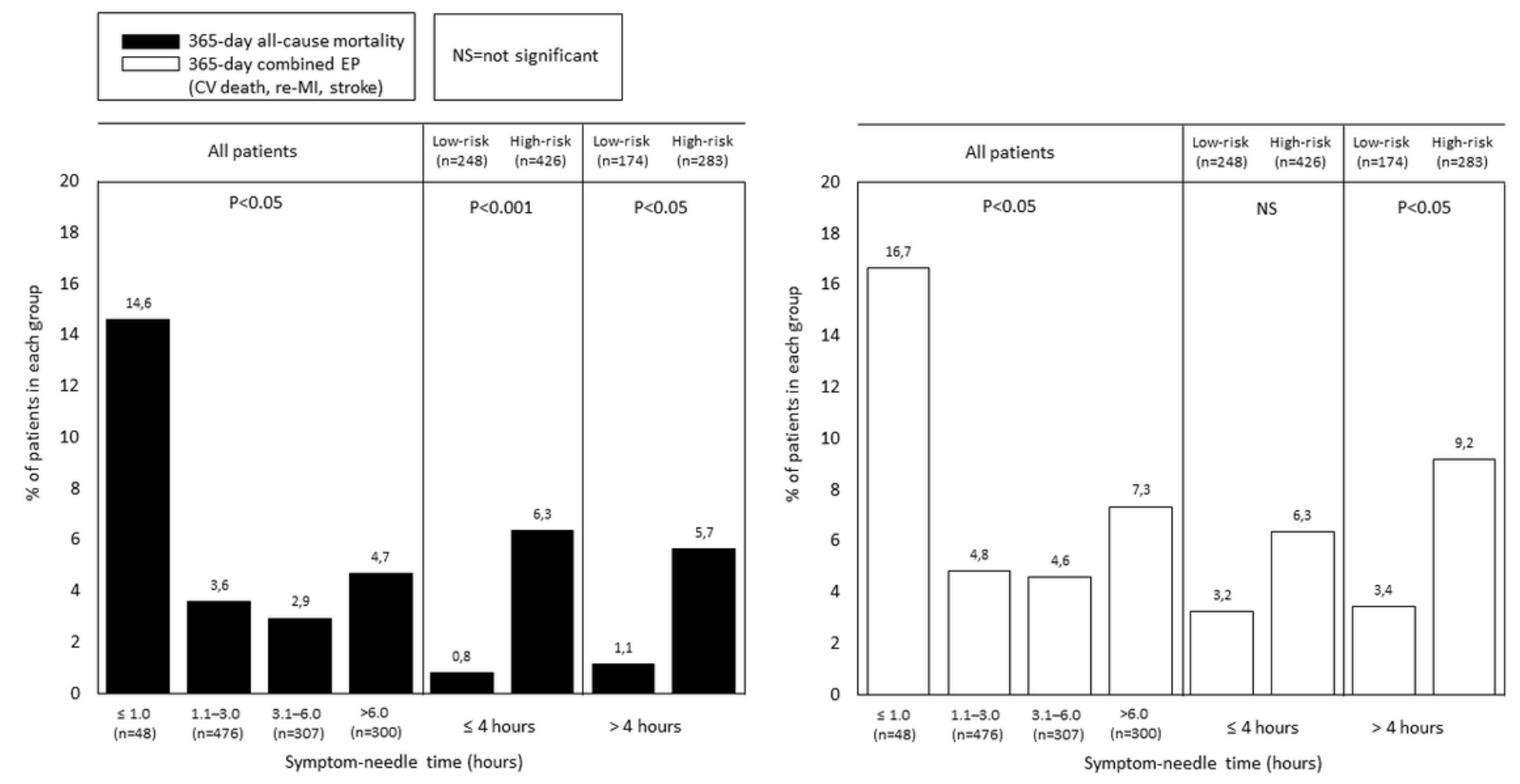

Figure 1

Incidence of all-cause mortality and the combined ischemic endpoint at one year in the cohort of 1131 patients. 